\title{
The relationship between stress shielding and bone resorption around total hip stems and the effects of flexible materials
}

Citation for published version (APA):

Huiskes, H. W. J., Weinans, H., \& Rietbergen, van, B. (1992). The relationship between stress shielding and bone resorption around total hip stems and the effects of flexible materials. Clinical Orthopaedics and Related Research, 274, 124-134.

Document status and date:

Published: 01/01/1992

\section{Document Version:}

Publisher's PDF, also known as Version of Record (includes final page, issue and volume numbers)

\section{Please check the document version of this publication:}

- A submitted manuscript is the version of the article upon submission and before peer-review. There can be important differences between the submitted version and the official published version of record. People interested in the research are advised to contact the author for the final version of the publication, or visit the $\mathrm{DOI}$ to the publisher's website.

- The final author version and the galley proof are versions of the publication after peer review.

- The final published version features the final layout of the paper including the volume, issue and page numbers.

Link to publication

\section{General rights}

Copyright and moral rights for the publications made accessible in the public portal are retained by the authors and/or other copyright owners and it is a condition of accessing publications that users recognise and abide by the legal requirements associated with these rights.

- Users may download and print one copy of any publication from the public portal for the purpose of private study or research.

- You may not further distribute the material or use it for any profit-making activity or commercial gain

- You may freely distribute the URL identifying the publication in the public portal.

If the publication is distributed under the terms of Article 25fa of the Dutch Copyright Act, indicated by the "Taverne" license above, please follow below link for the End User Agreement:

www.tue.nl/taverne

Take down policy

If you believe that this document breaches copyright please contact us at:

openaccess@tue.nl

providing details and we will investigate your claim. 


\title{
The Relationship Between Stress Shielding and Bone Resorption Around Total Hip Stems and the Effects of Flexible Materials
}

\author{
Rik Huiskes, Ph.D., HaRrie Weinans, M.S., AND Bert van Rietbergen, M.S.
}

\begin{abstract}
Bone resorption around hip stems is a disturbing phenomenon, although its clinical significance and its eventual effects on replacement longevity are as yet uncertain. The relationship between implant flexibility and the extent of bone loss, frequently established in clinical patient series and animal experiments, does suggest that the changes in bone morphology are an effect of stress shielding and a subsequent adaptive remodeling process. This relationship was investigated using strain-adaptive bone-remodeling theory in combination with finite element modeis to simuiate the bone remodeling process. The effects of stem material flexibility, bone flexibility, and bone reactivity on the process and its eventual outcome were studied. Stem flexibility was also related to proximal implant/bone interface stresses. The results sustain the hypothesis that the resorptive processes are an effect of bone adaptation to stress shielding. The effects of stem flexibility are confirmed by the simulation analysis. It was also established that individual differences in bone reactivity and mechanical bone quality (density and stiffness) may account for the individual variations found in patients and animal experiments. Flexible stems reduce stress shielding and bone resorption. However, they increase proximal interface stresses. Hence, the cure against bone resorption they represent may develop into increased loosening rates because of in-
\end{abstract}

From the Biomechanics Section, Institute for Orthopaedics, University of Nijmegen, The Netherlands.

Presented at the 19th Open Scientific Meeting of the Hip Society, Anaheim, California, March 9, 1991.

Reprint requests to R. Huiskes, Ph.D., the Biomechanics Section, Institute for Orthopaedics, University of Nijmegen, P.O. Box 9101,6500 HB Nijmegen, The Netherlands.

Received: May 7, 1991. terface debonding and micromotion. The methods presented in this paper can be used to establish optimal stem-design characteristics or check the adequacy of designs in preclinical testing procedures.

Will stress shielding limit the longevity of femoral implants? Orthopedic clinicians and scientists are searching for an answer. Stress shielding is a mechanical phenomenon, occurring in composites of stiff and flexible materials, and prominent in the femoral total hip arthroplasty (THA) configuration. ${ }^{15-18,21,26}$ A femur, in its natural state, carries its external (hip joint and muscle) loads all by itself. When provided with an intramedullary stem, it shares the load-carrying capacity with the implant. Where the same load was first carried by one structure, the bone, it is now carried by two, the stem and the bone. As a consequence, the bone is subjected to reduced stresses, hence stress shielded.

This mechanical phenomenon would be of academic interest only, were it not for its assumed role as a stimulus for bone resorption. In accordance with Wolff's Law, the reduction of stresses relative to the natural situation would cause bone to adapt itself by reducing its mass, either by becoming more porous (internal remodeling) or by getting thinner (external remodeling). ${ }^{7,10,11,27}$ These resorptive phenomena around hip stems have indeed been reported frequently from clinical roentgenographic studies. ., $, 13,20,28$ 
I sing dual-energy roentgenographic densitometry or absorptiometry techniques, bonemass reductions of up to $50 \%$ in the proximal femur, after four to seven postoperative vears, were recently found. ${ }^{20,28}$ In canine experiments with noncemented, ingrown total hip replacement, Turner et al. ${ }^{29}$ found up to $20 \%$ bone resorption in the proximal femur after six months postoperative in canine experiments. When the material of the prosthesis was changed from titanium to a more flexible material with a reduced elastic modulus, the amount of bone resorption after six months was notably less. ${ }^{13}$ Similar results were reported by Bobyn et al., ${ }^{2}$ who investigated the effects of massive and more flexible hollow hip stems on bone-resorption patterns in the dog. This effect of stem stiffness on the extent of bone resorption was also reported from clinical roentgenographic studies of patients by Engh and Bobyn, ${ }^{8}$ this time related to the thickness of the stem instead of its elastic modulus.

The bone resorption phenomena established in clinical series notwithstanding, few clinical problems have been reported up until now. Nevertheless, it is still uncertain whether the bone-remodeling process stops after a relatively short period. Recent information seems to suggest it does not. ${ }^{20,28}$ But even if it does, after a few years, a loss of proximal bone mass on the order of $50 \%$ provides little confidence for the time when these patients get older and become prone to falls or other accidents. The fixation strength provided by the remaining bone may then sometimes not be adequate to withstand the impact forces. Or, when revisions are needed, for whatever reason, adequate bone stock may not be available. Hence, investigating the bone-remodeling phenomena and their relationships with implant and patient characteristics seems to be of importance.

The occurrence of bone resorption around prosthetic stems on the one hand, and the establishment of stress-shielding on the other, by themselves, do not prove that these two phenomena are related. Factors like hor- monal influences and vascular interruptions could also be responsible. However, more resorption is found around stiff, canal-filling stems than around thinner and more flexible stems. This indicates a biomechanical effect, for it coincides with the effect on stress shielding. ${ }^{2,16,18,21}$

Assuming that the bone-remodeling effects around prostheses are indeed caused by biomechanical adaptation mechanisms, and neglecting other factors, this process can be studied analytically, using strain-adaptive boneremodeling theories. ${ }^{3,6,18}$ These theories are quantitative formulations of Wolf's Law, mathematical descriptions of the net bone modeling and remodeling process. When used in combination with finite element (FE) models, they can be applied to study the effects of implant parameters, such as stem shape, material, or bonding characteristics, on the long-term bone morphology. 1,14,17,18,25 It has been shown recently that results of animal experiments, in terms of long-term trabecular bone density and cortical bone morphology, can be predicted analytically to a reasonable detail with these methods. ${ }^{19}$

The purpose of this study was to investigate the effects of stem flexibility, bone stiffness, and bone reactivity on the bone-remodeling process around noncemented stems. Particularly emphasized is the question whether indeed, from a biomechanical point of view, flexible stems could be the answer to the resorption problem. For this purpose, the strain-adaptive bone-remodeling theory, used earlier to simulate animal experiments, ${ }^{19}$ is applied in a 3-D FE model of human hip replacement.

\section{MATERIALS AND METHODS}

A proximal femur was selected out of a stock of 160 embalmed specimens. This specimen was considered more-or-less average in shape and bone density, as confirmed by external dimensional measurements and visual roentgenographic inspection. The bone was scanned on a CT-scanner in slices of 4-mm thickness at 27 locations. (Fig. 1A). The CT-data was transferred to a graphics computer program. Based on the geometry of the 

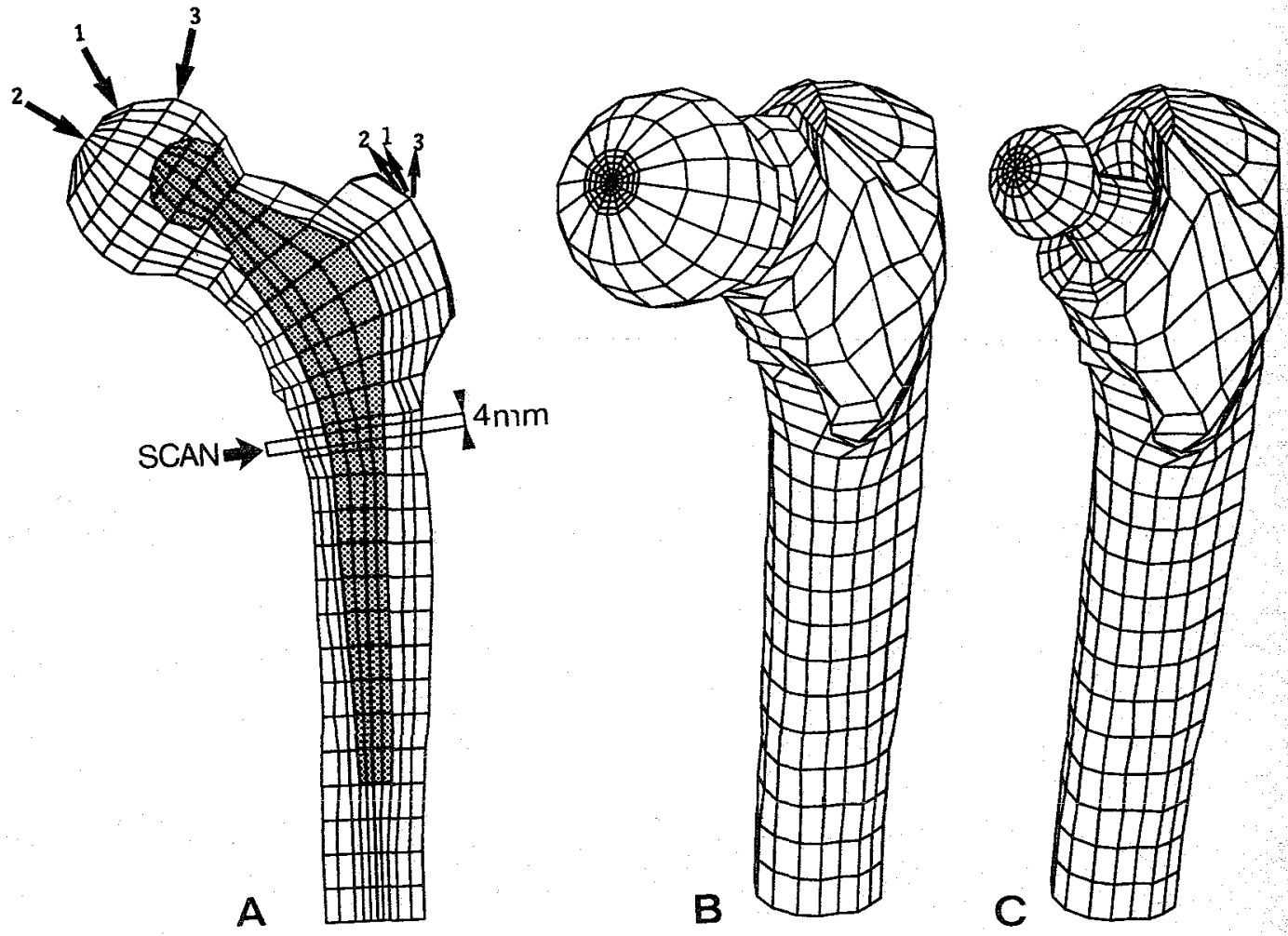

FIGs. 1A-1C. The finite element models used in the remodeling analysis. (A) Longitudinal section through the intact-bone model with the prosthesis projected. The Loading Cases 1,2, and 3 are indicated on the head and greater trochanter. Twenty-seven CT scans of 4-mm thickness were made of the intact bone, located in the center of each element layer. (B) Intact-bone model. (C) Model with prosthesis.

bone contours, a 3-D FE mesh was constructed with 8-node isoparametric brick elements (Figs. $1 \mathrm{~A}$ and $1 \mathrm{~B})$. In a second FE model, a prosthesis in the bone was represented (Figs. $1 \mathrm{~A}$ and $1 \mathrm{C}$ ). The prosthesis is symmetric relative to the midfrontal plane, and assumed fully bonded (osseointegrated) to the bone.

The average apparent density $\rho\left(\mathrm{gr} / \mathrm{cm}^{3}\right)$ in each element was determined from the CT-density values. The maximal CT-density value of all slices was identified and assumed equal to an apparentdensity value of $\rho=1.73 \mathrm{gr} / \mathrm{cm}^{3}$ (cortical bone). Using linear interpolation between the lowest and this maximal value, the CT-density distribution in the slices could be transformed to a corresponding apparent-density distribution. The apparent-density distributions in the 4-mm slices thus obtained, were extrapolated to the element layers concerned (Fig. 1A), which measure about $10 \mathrm{~mm}$ in thickness. The elastic moduli per element $\mathrm{E}(\mathrm{MPa})$ were determined from the apparent densities, using ${ }^{4}$

$$
\begin{aligned}
\mathrm{E} & =\mathrm{c} \rho^{3}, \\
\text { where } \mathrm{c} & =3790 .
\end{aligned}
$$

The FE program (MARC Analysis Corporation, Palo Alto, California) was integrated with a strainadaptive bone-remodeling simulation procedure (Fig. 2), which relates local, actual strain variables to gradual changes in bone density ${ }^{17}{ }^{7}$ This simulation process is based on a conservative (or site-specific) formulation of strain-adaptive bone-remodeling theory, which assumes that bone reacts to a local difference between actual strain values in the bone with prosthesis and the strain values at the same location in the intact bone., ${ }^{6,18}$ This procedure requires the definition of a remodeling signal, which represents the stimulus for strain-adaptive net bone remodeling, and of a remodeling rule, which is the mathematical description of the remodeling process.

The remodeling signal is based on the assumption that bone strives to normalize the average 


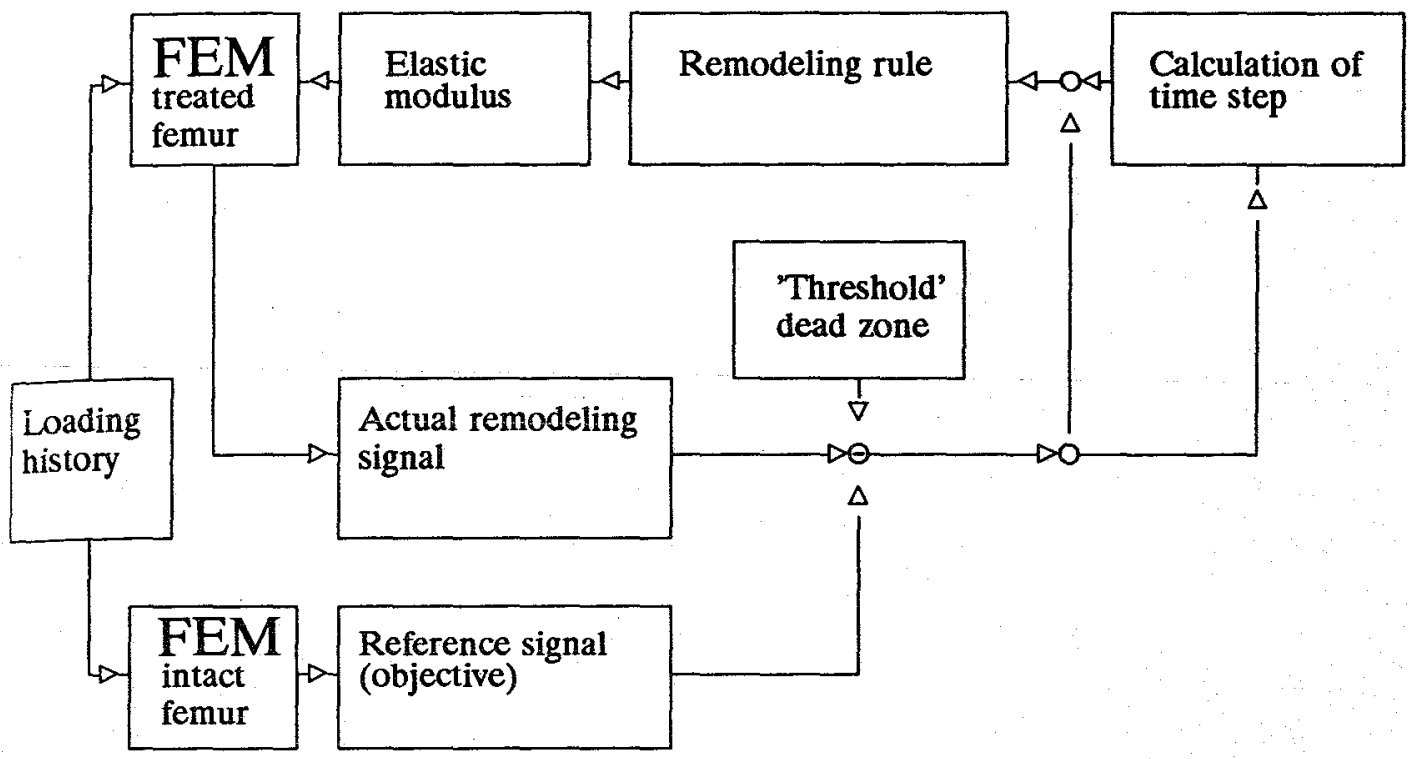

FIG. 2. Schematic overview of the strain-adaptive bone-remodeling simulation process. FEM, finite element model.

elastic energy per unit of mass for a particular loading history. The signal, average elastic energy per unit of mass, can then be expressed as

$$
\mathrm{S}=\frac{1}{\mathrm{n}} \sum_{\mathrm{i}=1}^{\mathrm{n}} \mathrm{U}_{\mathrm{i}} / \rho
$$

where $U_{i}$ is the strain-energy density (SED) in the bone for loading case $\mathrm{i}, \mathrm{n}$ is the number of loading cases considered, and $\rho$ is the apparent density. A similar signal was proposed by Carter et al ${ }^{3,5}$ The objective of the net bone-remodeling process can then be described as

$$
\mathrm{S}-\mathrm{S}_{\mathrm{ref}}=0 \text {, }
$$

where $S_{\text {ref }}$ is the signal value in the intact bone, at the same location where $S$ is measured in the bone with prosthesis, for the same loading history. Although equation (3) can already be considered a remodeling rule, two more refinements are added.

As suggested by Frost ${ }^{10}$ and experimentally confirmed by Maloney et al., ${ }^{22}$ true normalization of bone strains, in the sense of equation (3), does not occur. Hence, a minimum effective strain signal $\left(\mathrm{MES}^{11}\right)$ is necessary to stimulate remodeling. This can be seen as a dead zone in the remodeling process, measuring $(1 \pm \mathrm{s}) \mathrm{S}_{\text {ref. }} 1,18,31$

As suggested by Martin, ${ }^{23}$ the remodeling rate depends on the relative amount of pore surface available in the bone. This amount, a $\left(\mathrm{mm}^{2} /\right.$ $\mathrm{mim}^{3}$ ), can be expressed as a function of apparent. density $(a=a(\rho)$ ), using a geometric model for the pore shape. , $19,24^{2}$

The remodeling rule can then be expressed as the net remodeling rate $\mathrm{d} \rho / \mathrm{dt}$, according to

$$
\begin{aligned}
& \frac{\mathrm{d} \rho}{\mathrm{dt}}=\mathrm{a}(\rho)\left\{\mathrm{S}-(1-\mathrm{s}) \mathrm{S}_{\mathrm{ref}}\right\}, \quad \text { if } \mathrm{S}<(1-\mathrm{s}) \mathrm{S}_{\mathrm{ref}} \\
& \frac{\mathrm{d} \rho}{\mathrm{dt}}=0, \quad \text { if }(1-\mathrm{s}) \mathrm{S}_{\mathrm{ref}} \leq \mathrm{S} \leq(1+\mathrm{s}) \mathrm{S}_{\mathrm{ref}} \\
& \frac{\mathrm{d} \rho}{\mathrm{dt}}=\mathrm{a}(\rho)\left\{\mathrm{S}-(1+\mathrm{s}) \mathrm{S}_{\mathrm{ref}}\right\}, \quad \text { if } \mathrm{S}>(1+\mathrm{s}) \mathrm{S}_{\mathrm{ref}}
\end{aligned}
$$

Three loading cases out of a daily loading cycle are considered, according to Carter et al..$^{5}$ (Fig. 1A.) All loads work in the midfrontal plane of the prosthesis, hence no torsional component was included. The loads for the intact and the treated femur were equal relative to the geometries of the bone. Since the center of the prosthetic head does not coincide with the center of the natural head (Fig. 1A), the appropriate transformations of the hip-joint force had to be made to accomplish that.

In the remodeling analyses, the effects of several factors were studied: (1) the extent of the dead zone in the remodeling rule was reduced from $\mathrm{s}$ $=0.75$ to $\mathrm{s}=0.35$ to study the effects of differences in bone reactivity; (2) the stiffness characteristics of the bone were varied from $\mathrm{E}=\mathrm{c}^{3}$ [equation (1)] to $\mathrm{E}=\mathrm{c}(2 \rho)^{3}, 2 \rho \leq 1.73 \mathrm{gr} / \mathrm{cm}^{3}$, hence, a 
thicker cortex and trabecular bone twice as dense, to study the effects of a stiffer bone relative to the implant; and (3) the elastic modulus of the stem was varied from $\mathrm{E}=1.1 \times 10^{5} \mathrm{MPa}$ (titanium) to $\mathrm{E}$ $=0.2 \times 10^{5} \mathrm{MPa}$, to study the effect of a flexible, isoelastic stem material. In all these cases, a complete remodeling analysis was performed to predict the long-term morphology. In addition, FE analyses were performed for stem elastic moduli of $0.5 \times 10^{5} \mathrm{MPa}$ and $0.8 \times 10^{5} \mathrm{MPa}$. In these cases, no remodeling analyses were performed, but only the extent of 'stress shielding' and the values of implant/bone interface stresses in the immediate postoperative configuration were determined.

\section{RESULTS}

In the immediate postoperative configuration, the stimulus for strain-adaptive bone remodeling is determined by the initial difference between the actual signal $S$ and the reference (natural) value $S_{\text {ref }}$ hence by $S-S_{\text {ref. }}$. Where this initial stimulus is positive, bone formation will start; if it is negative, it represents the extent of stress shielding and resorption will start. The distributions of this initial stimulus in a mid-frontal section of the replacement configuration are shown in Figure 3 , for the titanium stem and for the more flexible isoelastic stem. Around the stiffer stem, stress shielding (a negative initial stimulus) is found in almost the whole medial cortex, and throughout a large part of the lateral one, along the length of the stem. A positive initial stimulus value of any real significance is only found near the distal tip of the stem. Around the flexible isoelastic stem some stress shielding is seen subperiosteally along the medial cortex, but to a much lesser extent. A large positive initial stimulus is found in the proximal/medial trabecular bone, around the flexible stem, so here bone density is expected to increase significantly.

The original, initial density distribution of the bone, according to the CT-scanner measurements, is shown in Figure 4. This is to be compared to the density patterns predicted around the titanium stem (dead zone $s$ $=0.75$ ) after long-term remodeling simulation (Figure 5). Severe bone resorption is pre-

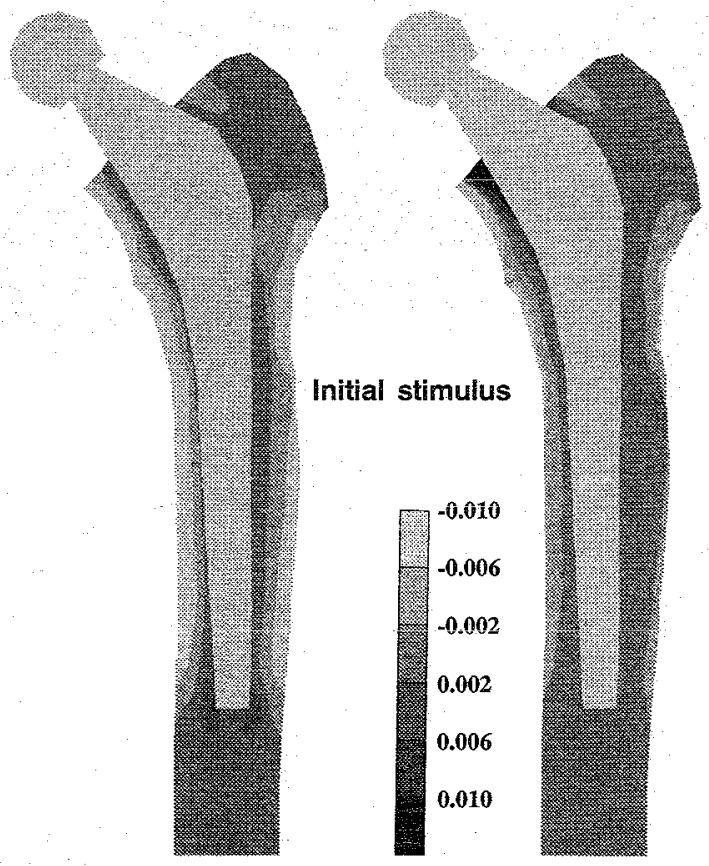

Titanium stem
FIG. 3. Initial (immediate postoperative) stimulus patterns $\left(\mathrm{S}-\mathrm{S}_{\mathrm{ref}}\right.$ ) around the (relatively stiff) titanium stem (left) and the flexible isoelastic stem (right). Units are Joules/gr and the values are averaged over the three loading cases. A negative value represents stress shielding, a stimulus for bone resorption; a positive value represents a stimulus for bone formation. 


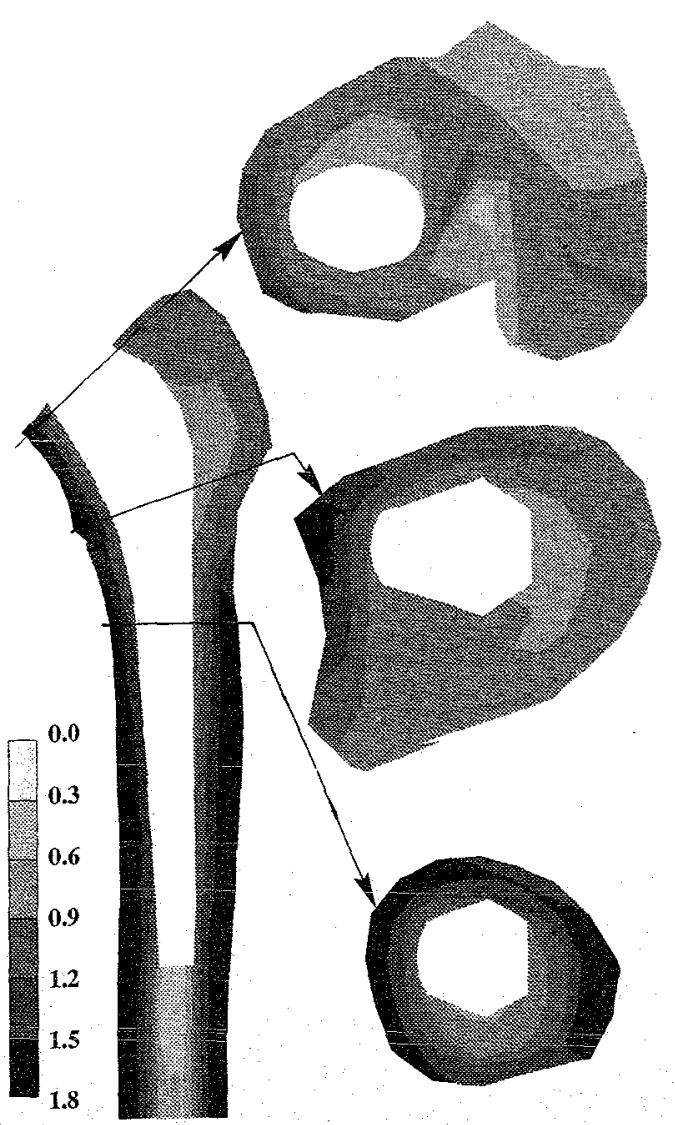

Initial Density

FIG. 4. Initial (immediate postoperative) apparent density distributions $\left(\rho \mathrm{gr} / \mathrm{cm}^{3}\right)$ in the proximal femur, as determined from the CT scans.

dicted proximally around the stem, except on the lateral side. Further down, cortical resorption in particular, but some trabecular densification is found at the medial edge of the prosthesis. Halfway down the stem one also sees densification at the lateral edge of the stem. At the tip of the stem, densification occurs all around to the extent that the cortices seem to have increased in thickness. The total amount of net bone loss predicted is $23 \%$ in this case, but most of this disappears proximally. Divided in four regions (Fig. 6), net bone losses of $68 \%, 35 \%$, and $3 \%$ are found from proximal to distal, and a gain of
$4 \%$ in the most distal region. The total amount of net bone loss in the greater trochanter, often used for roentgenographic measurements, is $35 \%$ in this case.

It is interesting to note, comparing Figures 3 and 5, that although the immediate postoperative stress shielding distribution (Figure 3) provides the initial stimulus for the bone-remodeling process, there is no direct linear relationship between these patterns and the eventual remodeling patterns (Figure 5 ). The initial stimulus patterns suggest, for instance, that the whole medial cortex along the stem

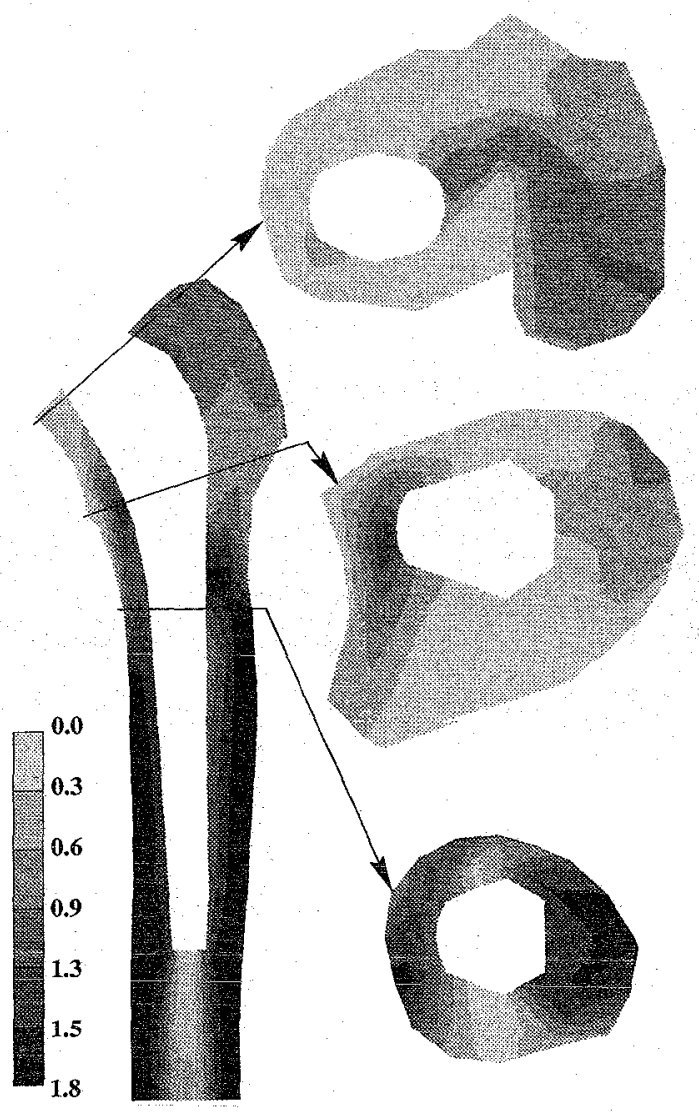

Final Density (Titanium stem)

FIG. 5. Final density distribution $\left(\rho \mathrm{gr} / \mathrm{cm}^{3}\right)$ after remodeling is completed around the titanium stem, as predicted by the simulation procedure. Dead zone, $s=0.75$; initial density according to Figure 4. 


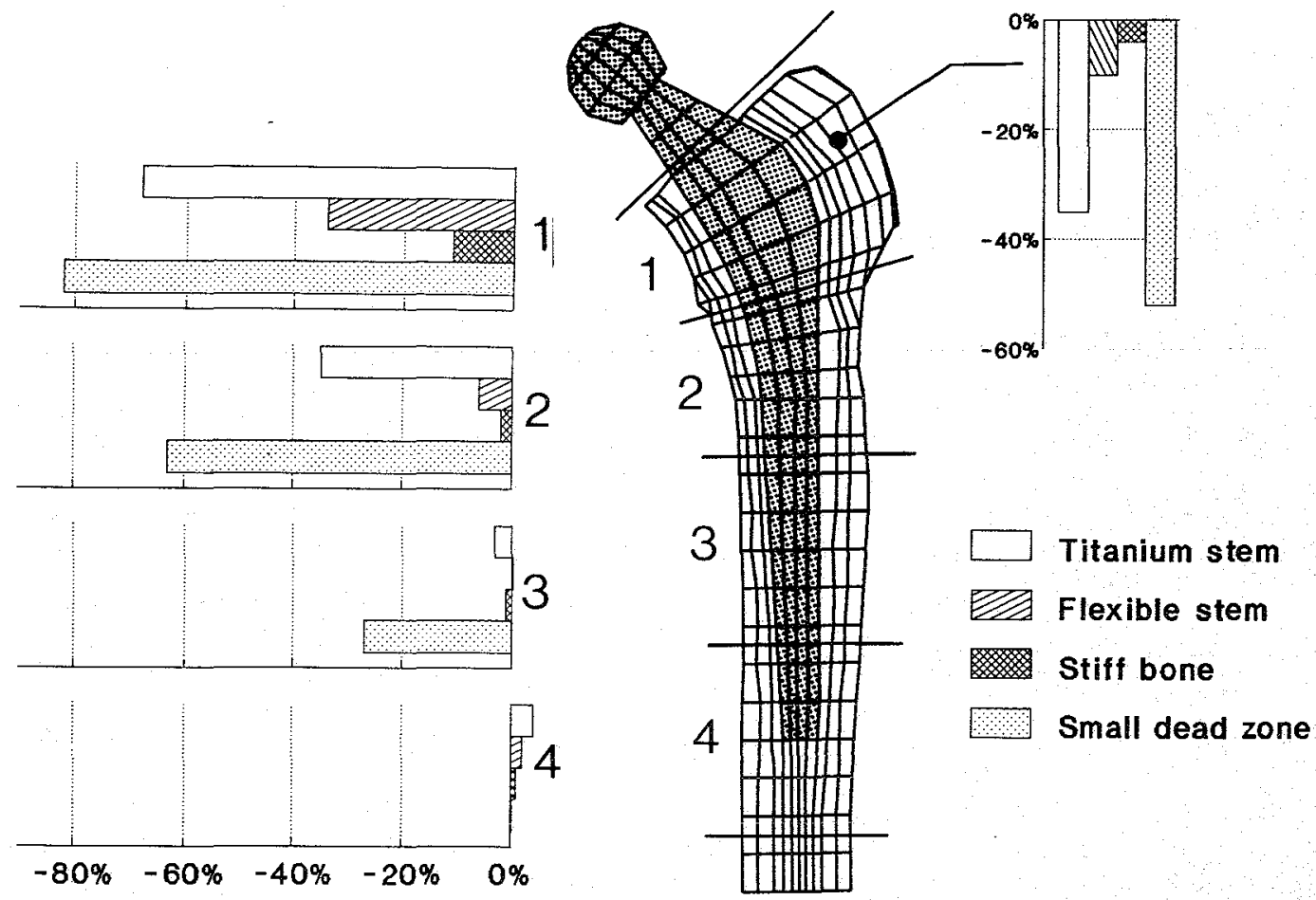

FIG. 6. A comparison of percentages of eventual bone loss in four regions and in the greater trochanter, as determined in the remodeling simulation of four cases. Each region includes all bone within it, but Region 1 does not include the greater trochanter.

would resorb, whereas, in fact, this is only seen proximally. Hence, the strain-adaptive bone-remodeling process is a nonlinear one and the eventual outcome can only be estimated from the initial stimulus up to a certain extent. First of all, this is caused by the dead zone in the bone-reactivity relationship. In addition, however, another mechanism plays a role. Because the initial stimulus for bone resorption is higher proximally, most bone mass disappears there in the first postoperative period. Hence, proximal bone density and stiffness are reduced in particular. As a result of this, the load transfer from prosthesis to bone shifts from proximal to distal, which increases the proximal stimulus for resorption even more, but reduces the distal one.

The long-term remodeling patterns are very susceptible to the properties of the bone and the stem, and to the width of the dead zone. Figure 6 compares the percentages of bone loss or gain in the four regions indicated and in the greater trochanter, as determined for the more flexible stem, the stiffer bone, and the reduced dead zone, respectively. Around the flexible (isoelastic) stem, the total amount of net bone loss reduces from $23 \%$ to $9 \%$. When a stiffer bone is assumed around the titanium stem, the total amount of net bone loss reduces from $23 \%$ to $4 \%$. Reducing the dead zone from $s=0.75$ to $s=0.35$ increases this amount from $23 \%$ to $41 \%$. In all cases, bone loss is more extensive proximal than further distal. It is interesting to note that the bone-density reductions in the greater trochanter give reasonable indications of overall bone loss (Figure 6).

Evidently, prosthetic stiffness is an important factor for stress shielding and subsequent 
bone remodeling. The lower the elastic modulus of the stem, the less bone is resorbed. Conversely, however, the more flexible the stem, the higher the proximal stem/bone interface stress. $^{15,16,21,26}$ These interface stresses may cause proximal stem debonding and relative (micro) motions at the interface. To relate both stress shielding and interface stresses to stem stiffness, FE analyses with the present model were performed using the same three loading cases as depicted in Figure 1A, assuming stem elastic moduli of $20,50,80$, and 110 $\mathrm{GPa}$; the first and the last of these are the same as already discussed relative to the remodeling analyses. As a measure for the proximal interface stresses, the maximal Von Mises stress of the three loading cases in the second nodal point from proximal in the medial, midfrontal plane was taken. As a measure for stress shielding, the initial stimulus value $\mathrm{S}-\mathrm{S}_{\mathrm{ref}}$ was determined, averaged over four layers of subperiosteal elements in the medial/anterior quadrant of the bone. The result is shown in Figure 7, whereby the interface-stress value is taken as $100 \%$ for the most flexible implant, and the initial-stimulus

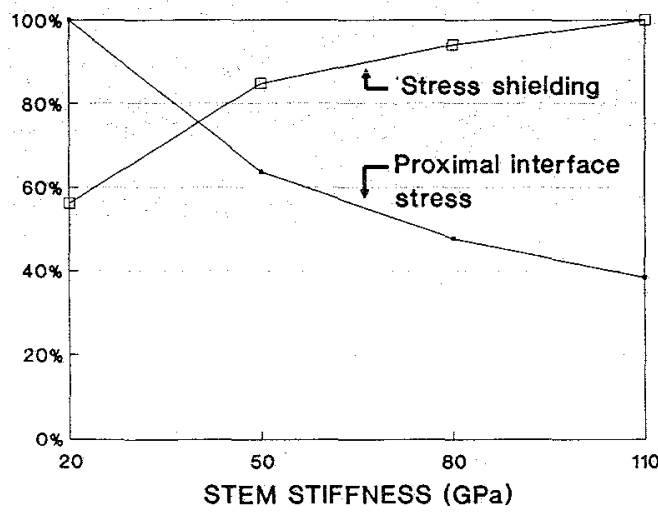

FIG. 7. The relative relationships between stress shielding and proximal interface stress with stem stiffness. Stress shielding is expressed relative to the case of the titanium stem (100\%) and interface stress is expressed relative to the isoelastic stem with the same elastic modulus as bone (100\%). This graph clearly illustrates the principle design conflict. value is taken as $100 \%$ for the stiffest implant. This graph shows a number of interesting aspects. Clearly, the relationships between implant stiffness and proximal interface stresses or stress shielding are nonlinear ones. Both interface stresses and stress shielding level off when the stiffness of the stem increases. This means that the higher the elastic modulus of the stem, the less of an effect a further increase will have. On the other side, one sees that when the stem gets more flexible, it progressively increases interface stresses and progressively reduces stress shielding. It must be noted, that, although the qualitative aspects of these two curves may be valid in general, their precise courses also depend on implant design, implant/bone bonding characteristics, and fit. The design conflict between requirements for minimal stress shielding and minimal interface stress is immediately obvious from the curves in Figure 7.

\section{DISCUSSION}

The use of strain-adaptive bone remodeling theory for computer-simulation models, in combination with $\mathrm{FE}$ analysis, for the prediction of long-term adaptations of bone morphology is relatively new. Experience has shown that valid predictions can be made. The remodeling signal $S$ (elastic energy per unit of bone mass averaged for a loading history) was used in optimization schemes and remodeling rules to recreate the trabecular density patterns of the proximal femur satisfactory. ${ }^{1,3,5,17,30}$ Recently, a similar remodeling scheme as the one presently applied was used to successfully simulate long-term bone remodeling around hip stems in canine experiments. ${ }^{19}$ However, there are many unknowns in the remodeling process, and the simulation model used is purely empirical. The authors do not know whether elastic energy per unit of bone mass is the actual stimulus for remodeling; it simply yields valid predictions when used as such. On one hand, the 
conservative (or site-specific) remodeling rule, according to which an actual value of the remodeling signal is always compared to its natural value, has shown to be insensitive to the precise loading conditions assumed. ${ }^{18}$ Conversely, however, the rule does force one to assume that the loads are equal before and after the operation. For most patients, this will not be the case; otherwise, they would not have needed a hip arthroplasty in the beginning. Furthermore, the FE model represents one particular THA configuration: one particular stem shape, one particular bone shape, a perfect fit, and a fully-bonded (ingrown) interface. The authors know that the extent of interface bonding has a significant effect on the stress-shielding patterns. ${ }^{16}$ Hence, the results presented here are to be viewed as trends, and the conclusions drawn relate to the qualitative effects of the parametric variations studied, rather than to the absolute numbers produced.

One important aspect of the remodeling rule applied is the consideration of a dead zone: a certain level of signal abnormality must be exceeded before the bone responds. The concept of such a threshold was first introduced by Frost $^{10}$ as a minimum inhibitory signal. The authors have found that a dead zone must be included in the simulation model to obtain valid results. ${ }^{19,31}$ Maloney et $a l .,{ }^{22}$ testing retrieved proximal femurs with cemented prostheses, found that complete strain normalization does not occur in the bone. This finding can only be explained when assuming a dead zone in the remodeling response. ${ }^{31}$ The precise extent of the dead zone is, of course, unknown. Frost ${ }^{12}$ suggested that it may depend on individual metabolic factors, and may even vary throughout life for a particular individual. Although the authors concluded from canine simulations ${ }^{19}$ that it measured about $\pm 35 \%$ of the natural stimulus value, this may well be different for humans. In any case, it was shown here that the extent of the dead zone has a major effect in particular on the amount of bone resorption around hip stems and not as much on the resorption patterns. When reducing the zone from $\pm 75 \%$ to $\pm 35 \%$ of the natural stim ulus value, the total amount of bone loss in creased from $23 \%$ to $41 \%$. If, indeed, thi: zone is subject to vast individual variations this may well explain individual differences in bone-resorption patterns found in clinical patient series.

The extent of stress shielding of bone around a hip stem depends on the interface bonding characteristics (fit, coating, and ingrowth characteristics) and on stem stiffness. ${ }^{15-18,21}$ Stem stiffness depends on stem thickness and elastic modulus, whereby it must be appreciated that a $10 \%$ increase in stem thickness produces a $33 \%$ increase in (bending) stiffness. As discussed above, a reduction of the stem elastic modulus by a factor of 5.5 (an isoelastic material with a modulus similar to cortical bone) reduces the amount of long-term bone loss considerably, from $23 \%$ to $9 \%$. However, a similar reduction is obtained for a titanium stem, when bone-bending stiffness is increased. Hence, the important causative factor for bone resorption is implant stiffness relative to bone stiffness, rather than implant stiffness in an absolute sense. This also implies that individual differences between bone responses in patient series may be explained by variations in bone quality, as was also suggested by Engh and Bobyn. ${ }^{8}$

The reduction of stem stiffness to reduce stress shielding and prevent severe bone resorption is an attractive design concept. Indeed, a number of manufacturers are now experimenting with flexible (isoelastic) materials. It is also known, however, that flexible stems create high proximal stem/bone interface stresses, which may cause interface debonding and relative motions, possibly affecting implant loosening. ${ }^{15,16,21,26}$ When evaluating the effects of stem flexibility on both proximal interface stresses and the extent of stress shielding, one finds that this produces a conflict in design requirements. The curves suggest (Fig. 7) that an optimal stem flexibility exists that reduces interface stresses to an acceptable level, and, at the same time, produces only moderate stress shielding. To find 
this optimal value, however, one needs to find out which level of interface stress is acceptable. In the meantime, flexible stem materials should be considered with caution, and it is safe to assume that flexible stems require stronger proximal interface bonds than stiff stems.

An important, unanswered question is whether the strain-adaptive bone resorption process continues or whether it stops after a particular postoperative period. Many authors suggest it stops after a few years, based on roentgenographic evaluations of patient series. It must be appreciated, however, that traditional roentgenographs are unsuitable to accurately determine net changes in bone mass of less than $30 \%$. A recent clinical study, using dual-energy roentgenograph densitometry, indicated that remodeling does continue up to seven years postoperatively. ${ }^{20,28}$ The remodeling simulations discussed here were all continued for 20 iterative increments and virtually converged (although the simulation of the small dead zone was to a somewhat lesser extent). This means that the results represent the final morphology. In simulating canine experiments, ${ }^{19}$ it was possible to relate the time scale in the simulation step to a realistic, biologic one. However, the same time scale as for the canine will certainly not be valid for the human. Hence, it is not possible yet to relate the course of the simulation process directly to the clinical process in terms of years. In the simulation process, the remodeling rate decreases progressively. Hence, the largest changes in bone mass per unit of time occur in the first increments and then gradually reduce. This implies that the question of the postoperative process duration can only be answered through long-term clinical studies with accurate roentgenographic techniques. ${ }^{20,28}$ Conventional roentgenographic techniques are simply not accurate enough to answer that question.

Based on this study, taking into account the relative uncertainties of the simulation model applied, the following conclusions can be drawn: (1) The results of the strain-adaptive bone-remodeling simslations sustain the hypothesis that bone resorption around hip stems is governed by stress-shielding mechanisms. (2) For these simulation models to predict realistic results, a dead zone in the response of bone to an abnormal remodeling stimulus must be assumed. (3) The extent of the dead zone has a significant effect on the amount of bone eventually resorbed. (4) The amount of bone resorption around the stem is equally affected by implant stiffness and initial bone stiffness. (5) The adequacy of prosthetic designs relative to requirements of minimal bone loss can be preclinically tested in strain-adaptive bone-remodeling simulation models. (6) Bone-density changes in the greater trochanter give reasonable indications of overall bone-remodeling changes. (7) The question of the duration of the postoperative bone-remodeling process around hip stems can not be answered with traditional roentgenographic methods. (8) Flexible (isoelastic) stems reduce bone resorption, but require stronger interface bonds than stiffer stems to prevent proximal interface debonding and micromotions. Flexible stems as a cure for bone resorption could provoke results that are worse than the disease itself.

\section{REFERENCES}

1. Beaupré, G. S., Or, T. E., and Carter, D. R. An approach for time-dependent bone modeling and remodeling - application: A preliminary remodeling simulation. J. Orthop: Res., 85:662, 1990.

2. Bobyn, J. D., Glassman, A. H., Goto, H., Krygier, J. J., Miller, J. E, and Brooks, C. E.: The effect of stem stiffness on femoral bone resorption after canine porous-coated total hip arthroplasty. Clin. Orthop. 261:196, 1990.

3. Carter, D. R., Fyhrie, D. P., and Whalen, R. T.: Trabecular bone density and loading history: Regulation of connective tissue biology by mechanical energy. J. Biomech. 20:785, 1987.

4. Carter, D. R., and Hayes, W. C.: The behavior of bone as a two-phase porous structure. J. Bone Joint Surg. 59A:954, 1977.

5. Carter, D. R., Orr, T. E., and Fyhrie, D. P.: Relationships between loading history and femoral cancellous bone architecture, J. Biomech. 22:231, 1989.

6. Cowin, S. C., and Hegedus, D. H.: Bone remodeling I: Theory of adaptive elasticity. J. Elasticity $6: 313$, 1976.

7. Currey, J.: The mechanical adaptations of bone Guildford, U.K., Princeton University Press, 1984.

8. Engh, C. A., and Bobyn, J. D.: The influence of stem 
size and extent of porous coating on femoral bone resorption after primary cementless hip arthroplasty. Clin. Orthop. 231:7, 1988.

9. Engh, C. A., Bobyn, J. D., and Glassman, A. H.: Porous coated hip replacement: The factors governing bone ingrowth, stress shielding, and clinical results. J. Bone Joint Surg. 69:45, 1987.

10. Frost, H. M.: In Thomas, Charles C. (ed.): Laws of Bone Structure, Springfield, IL, 1964.

11. Frost, H. M.: Vital Biomechanics. Proposed general concepts for skeletal adaptations to mechanical usage. Calcif. Tissue Int. 42:145, 1987.

12. Frost, H. M.: Personal Communication, 1990.

13. Galante, J. O.: Determinants of stress shielding - design vs. materials vs. interface. The Hip Society, 19 th Open Scientific Meeting, Anaheim, CA, March 10 1991.

14. Hart, R. T., Davy, D. T., and Heiple, K. G.: A computational method of stress analysis of adaptive elastic materials with a view toward application in strain induced remodeling. J. Biomech. Eng. 106:342, 1984.

15. Huiskes, R.: Some fundamental aspects of humanjoint replacement. Acta Orthop. Scand. 5 I(Suppl.): 185,1980 .

16. Huiskes, R.: The various stress patterns of pressfit, ingrown, and cemented femoral stems. Clin. Orthop. 261:27, 1990.

17. Huiskes, R., Weinans, H., and Dalstra, M.: Adaptive bone remodeling and biomechanical design considerations for noncemented total hip arthroplasty. Orthopedics, 12:1255, 1989.

18. Huiskes, R., Weinans, H, Grootenboer, H. J., Dalstra, M., Fudala, B., and Slooff, T. J.: Adaptive bone-remodeling theory applied to prosthetic-design analysis. J. Biomech. 20:1135, 1987.

19. Huiskes, R., Weinans, H., Rietbergen, B. van, Sumner, D. R., Turner, T. M., and Galante, J. O.: Validation of strain-adaptive bone remodeling analysis to predict bone morphology around noncemented THA. Trans. 37th Annual ORS, Anaheim, California, March 4-7, Vol. 1, 1991. p. 105.

20. Kiratli, B. J., Heiner, J. P., McKinley, N., Wilsen, M. A., and McBeath, A. A.: Bone mineral density of the proximal femur after uncemented total hip arthroplasty. Trans. 37th Annual ORS, Anaheim, California, March 4-7, Vol. 3, 1991, p. 545.

21. Lewis, J. L., Askew, M. J., Wixson, R. L., Kramer, G. M., and Tarr, R. R.: The influence of prosthetic stem stiffness and of calcar-collar contact on stresses in the proximal end of the femur with a cemented femoral component. J. Bone Joint Surg., 63A:280, 1984.

22. Maloney, W. J., Jasty, M., Burke, D. W., O'Conner, D. O., Zalenski, E. B., Bragdon, C., and Harris, W. H.: Biomechanical and histologic investigation of cemented total hip arthroplasties. A study of autopsy-retrieved femurs after in vivo cycling. Clin Orthop. 249:129, 1989.

23. Martin, R. B.: The effects of geometric feedback in the development of osteoporosis. J. Biomech. 5:447, 1972.

24. Martin, R. B.: Porosity and specific surface of bone. CRC Critical Reviews in Biomedical Engineering, 10:179, 1984.

25. Orr, T. E., Beaupré, G. S., Carter, D. R,, and Shurman, D. J.: Computer predictions of bone remodeling around porous-coated implants. J. Arthroplasty $5: 191,1990$.

26. Otani, T., Whiteside, L. A., and White, S. E.: Strain distribution changes in the proximal femur caused by metallic and flexible composite femoral components under torsional load. Trans. 37th Annual ORS, Anaheim, California, March 4-7, Vol. 1, 1991, p. 267.

27. Roesler, H.: The history of some fundamental concepts in bone biomechanics. J. Biomech. 20:1025, 1987.

28. Steinberg, G. G., McCarthy, C. K., and Baran, D. T. Quantification of bone loss of the proximal femur after total hip arthroplasty. Trans. 37th Annual ORS, Anaheim, California, March 4-7, Vol. I, 1991, p. 221.

29. Turner, T. M., Sumner, D. R., Urban, R. M., Ri vero, D. P., and Galante, J. O.: A comparative study of porous coatings in a weight-bearing total hip arthroplasty model. J. Bone Joint Surg. 68A:1396, 1986.

30. Weinans, H , Huiskes, R., and Grootenboer, H. J. Convergence and uniqueness of adaptive bone remodeling. Trans. 35th Annual ORS, Las Vegas, $\mathrm{Ne}$ vada, February 6-9, 1989, p. 310.

31. Weinans, H., Huiskes, R., and Grootenboer, H. J.: A hypothesis concerning minimal bone density threshold levels as final stages of bone remodeling. Trans. 36th Annual ORS, New Orleans, Louisiana, Febr. 5-8, 1990, p. 79. 